\title{
Article
}

\section{Who knows? Youth work and the mise-en- scene: reframing pedagogies of youth participation}

Batsleer, Janet, Thomas, Nigel Patrick and Pohl, Axel

Available at http://clok.uclan.ac.uk/28929/

Batsleer, Janet, Thomas, Nigel Patrick ORCID: 0000-0002-5310-9144 and Pohl, Axel (2020) Who knows? Youth work and the mise-en-scene: reframing pedagogies of youth participation. Pedagogy, Culture \& Society, 28 (2). pp. 205-221. ISSN 1468-1366

It is advisable to refer to the publisher's version if you intend to cite from the work. http://dx.doi.org/10.1080/14681366.2019.1627484

For more information about UCLan's research in this area go to http://www.uclan.ac.uk/researchgroups/ and search for < name of research Group>.

For information about Research generally at UCLan please go to http://www.uclan.ac.uk/research/

All outputs in CLoK are protected by Intellectual Property Rights law, including Copyright law. Copyright, IPR and Moral Rights for the works on this site are retained by the individual authors and/or other copyright owners. Terms and conditions for use of this material are defined in the policies page.

\section{CLoK}

Central Lancashire online Knowledge www.clok.uclan.ac.uk

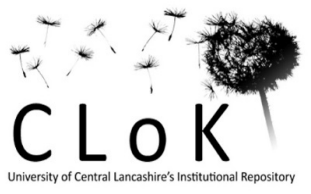




\section{Who knows? Youth work and the mise-en-scene: Reframing pedagogies of youth participation}

Janet Batsleer $^{\mathrm{a} *}$, Nigel Patrick Thomas ${ }^{\mathrm{b}}$ and Axel Pohl ${ }^{\mathrm{c}}$

Education and Social Reseach Institute, the Manchester Metropolitan University; ${ }^{b}$ The Centre for Children and Young People's Participation, University of Central Lancashire, Preston, UK; ${ }^{c}$ Institute for Social Work and Social Spaces, University of Applied Sciences, St. Gallen, Switzerland

Janet Batsleer

Reader in Education

The Manchester Metropolitan University

Brooks Building

53 Bonsall Street

Manchester

M15 6GX

Email: J.Batsleer@mmu.ac.uk

Mobile: +447729360857 


\section{Who knows? Youth work and the mise-en-scene: Reframing pedagogies of youth participation}

\section{Abstract}

Drawing on the PARTISPACE research (www.partispace.eu) and particularly on findings from three of eight European cities included into the study, this article asks how bringing to the surface the dramatic and theatrical practices underlying the metaphor of performance might contribute to a better understanding of youth participation. It considers the spaces, temporalities, actors and audiences, and atmospheres of youth participation projects. Youth workers and young people in these space/times can be seen as actors in the drama of participation; cast in their roles and caught up in power play, both small scale) and sometimes on a larger political stage, as in the context of the UK referendum on membership of the European Union. The micropolitics of group inclusions and exclusions which are pushed beyond the boundary in Youth Council spaces take centre stage in the drama of the Youth Club. Attention to ambivalence in the work of youth workers leads to a discussion of the needs of such pedagogues.

Keywords: participation; youth work; performance; ambivalence

\section{Introduction}

Youth work can be conceived of as following a curriculum, and the issue of how agendas of learning develop in informal settings beyond school has been much discussed (Ord, 2007; Young, 2006; Bright, 2015; St Croix, 2016). Radical democratic education traditions, rooted in experiential and critical models of learning, traditions of social education and social pedagogy, as well as practices which seek to develop civic agency and capabilities all have a home in this diverse body of practice and it is in such contexts that the issue of what forms (if any) a curriculum might take has been discussed. Not all traditions of youth work however, conceive of it as a form of education or personal development (Cooper, 2018). Terms such as 'curriculum' or 'education' may, overemphasising 'outcomes of learning' become too school-like and 'pedagogised', neglectful of those youth work traditions concerned, on the one hand with wellbeing, and on the other hand, with politics and (self-)empowerment. It has 
recently been argued that in its most radical and democratic forms, youth work seeks to engage broader social and political institutions, the actors and processes of democracy, as part of a wider social justice project. It does this in order to increase recognition and responsiveness to young people and their views (Heathfield and Fusco, 2015). Here theorisations of youth work overlap with theorisations of citizenship education and youth participation. This article seeks to bring rich ethnographic findings to bear on these discussions, reframing the analysis of both youth work and youth participation practices as performative pedagogies.

In the PARTISPACE research ${ }^{1}$ into the spaces and styles of young people's participation in eight European cities, the role of the youth worker, animateur or pedagogue came to the fore in a number of settings ${ }^{2}$. Rys Farthing has usefully analysed the discourses of youth participation and the critique of them, developing the following definition for the purposes of her study: 'youth participation is a process where young people as active citizens, take part in, express views on and have decision making power about issues that affect them.' The PARTISPACE study adopted a broader definition in order to enable a wider lens and recognition of participation practices; 'biographical selfdetermination in the public and through public institutions', a conceptualisation which was then operationalised in a research programme that asked 'what young people do in public spaces and what it means to them' in order to be able to develop a grounded theory of how (youth cultural) styles, social spaces and recognition interplay with institutional arrangements in young people's biographical pathways into diverse forms of citizenship. In this article we analyse youth participation as a range of practices in different settings, with a focus on the roles of different actors and the staging of participation - in other words, on participation as performance. The analogy of dramatic presentation seems to us a fruitful one, heuristically at least, in a number of ways:

\footnotetext{
${ }^{1}$ See Walther et al. (2019) for detailed accounts on the study.

${ }^{2}$ The term informal and non-formal learning are often used interchangeably, the first in UK and the second in the rest of Europe. In this article we use the term non-formal learning to distinguish the settings in which a pedagogue/youth worker is deliberately employed but which do not primarily exist to support education defined by the school curriculum.
} 
It enables us to ask questions about who are the actors, who is the director, the different ways in which those roles are made available, experienced and performed, and the range of possible relationships between actors and directors. It also raises the question of who constitutes the audience for this performance, and what is their part in the drama of participation.

It also enables us to ask questions about the staging of participation - its physical location, how this is chosen, the explicit or implicit meaning of this and its impact on the actors (about the 'mise-en-scène', to use another term from theatre and film). It also raises questions about what happens backstage, in Goffman's terms, and how this may be distinct from the performance on stage (1959). Finally, the analogy can help to open up questions about the script. How far is this written in advance and presented to the actors, and to what extent is there scope, as has often been asserted in youth work literature, for improvisation? (Bright, 2015; Davies, 2010)

The working assumption of PARTISPACE was that all these issues play out differently in formal, non-formal and informal settings, in terms of the role of the youth worker or other pedagogue, the physical and social context for the performance, the space for agency and self-direction by young people and their autonomous engagement with others off the stage.

\section{Sources of Discussion}

In the present article we explore specifically the staging of youth participation in the formal settings of youth councils and in non-formal settings such as youth clubs, youth houses and youth projects in all of which the participation is supported and facilitated by a youth worker or other pedagogue. On the basis of evidence from the PARTISPACE research, we consider the ways in which the practices of pedagogues, and the assumptions about young people embedded in those practices, shape and constrain the forms of possible participation. We look at to what extent these negotiations of relationship turn on a sense of what is visible and what invisible, what is legitimate and illegitimate to acknowledge and to voice, drawing on and developing Goffman's account of 'performance' as a framework as well as his use of the concepts of 'front stage' and 'back stage'. Clearly the discussion of social life as performed has developed 
significantly since Goffman's work and has been used, especially following the work of Judith Butler (for example, Butler, Zizek and Laclau, 2000), in the analysis of power relationships, an aspect of social relations which Goffman himself never explicitly explored.

The discussion here does indeed encounter issues of power. In the wider research project on which this article draws, the theorisation of power relations in participation has turned to a contemporary philosophical discussion of recognition, drawing especially on Butler's account of 'the right to appear', and on Ranciere's discussion of 'police' and 'politics'. (Authors, 2019 forthcoming). These discussions extend the well established analyses (following Foucault) of discourses of 'participation' as a form of governmentality (Cooke and Kothari, 2002). It is therefore unsurprising that in the account which follows, complex practices of inclusion and exclusion come to the fore. To demonstrate these dynamics of appearance and recognition, inclusion and exclusion further, we became interested in what happens when we restore a series of buried metaphors from the work of theatre to the analysis of social interactions

For example, the critique of participation as tokenism has been widely engaged with in academic literature (Percy-Smith, 2010; Farthing, 2012) but here we present evidence of how this awareness is actively negotiated on the ground. We want to know who or what are the audiences for these performances of participation, and how the youth workers and other pedagogues find themselves called upon to both perform and at the same time tacitly acknowledge the limits of tokenistic and manipulative practices. Equally, we see how young people exercise agency in these spaces, while both knowing and not knowing how youth workers or pedagogues are shaping the mise-en-scène. There are echoes here of both recent work and long-established work on student voice (Taylor and Robinson, 2009; Charteris and Simardon, 2018) where the presence of multiple scripts and contradictory legitimations is widely acknowledged.

If, as Gert Biesta (2009) has influentially argued, politics and democratic practice cannot be taught but only fostered and fuelled, then it is important to see where the working practices of people employed variously as pedagogues, animateurs, youth workers or social workers can be recognised as adding to that fuel and that fire, and where they damp things down. We will analyse the practice of youth workers and other pedagogues in fostering, fuelling (or not) democratic practices (Biesta, Lawy and Kelly, 
2009) among largely currently disenfranchised children/young people. From now on, for the sake of brevity, all such practitioners will be referred to as youth workers.

All in all, the PARTISPACE study comprised 48 ethnographic case studies of a spectrum of young people's practices starting from hanging around, moving through playing street music and drawing graffiti to more formally organised settings such as youth organisations or youth councils. The sampling of the case studies was based on a mapping process of youth participatory constellations in eight cities covered in the study. The mapping was based on about 200 expert interviews and 100 group discussions with young people from all socio-economic, educational and youth cultural backgrounds together with city walks. This process led us to choose 6 exemplary settings per city to dig deeper into the constellations of styles, spaces and participation. The ethnography of each setting consisted of participant observation of the activities of the groups of young people lasting from several weeks to many months. These observations were contrasted with occasional group and expert interviews in the context of the cases plus more than 100 biographical interviews with key characters of the activities. In this paper, we are drawing on fieldnotes made during participant observation in Manchester, Gothenburg, and Frankfurt (referred to in references as M, G and $\mathrm{F}$ from now on $)^{3}$. We then explore the roles of actors in these space/times of participation and give an account of the atmospheres of participation, the energies and movements we found. Discussions of youth work especially in public policy can seem to position youth workers as little more than 'street level bureaucrats' (Lipsky, 1980), social workers (Schwanenflügel and Walther 2016) or community police. Ethnographic accounts can both deepen and complexify this (Thole et al., 2011). We explore the subject positions and spatial positioning available to youth workers in relation to other actors and audiences, especially young participants in both and youth

\footnotetext{
${ }^{3}$ There is not enough space in this article to discuss the methodology of the large comparative study from which the evidence here is drawn, but a selection of fieldnotes from each city were translated and analysed in cross-consortium meetings between 2015 and 2017 and it is these translations which are presented here. Extracts from fieldnotes are presented in italics with the city of origin noted in abbreviated form.
} 
councils and youth clubs.

Initially we give an account of some of the physical spaces and time frames in which we observed youth work practice; what could be termed the preparation of space for the staging of participation.

\section{Places and Times: : Setting the Stage for Inclusion/Exclusion}

All the Youth Councils in the study have their offices in municipal buildings, in places of some, though not necessarily great, prestige. In contrast the Youth Centres are in the poorest neighbourhoods of the same cities. There is a remarkable similarity in this across the three cities of Manchester, Gothenburg and Frankfurt, as the following extracts from fieldnotes show. First a description from Gothenburg of a clean, tidy, friendly space, smelling of coffee and oranges:

'an office space in the Town Hall. The office is open twice a week, between 3 and 6 p.m., Mondays and Wednesdays. Most of the members start showing up at 4, when they are done with school activities. The office is equipped with a large rectangular table, chairs, a whiteboard, a computer and a projector, and an adjacent kitchen where participants take coffee, chocolate drinks, sandwiches and fruit.' (G)

The Frankfurt Council is similarly well equipped and set out as an office.

The (...) has its office in one of the city council's buildings in Frankfurt's inner city. The building houses several smaller departments of the municipality but also a number of welfare organisations and social initiatives. The YSR disposes of a 20 square meters' office which is equipped with a desk with telephone and computer, a copying machine and several couches. Usually the office is used by the (adult) manager and the council spokesperson to do administration tasks. But, it is also the meeting place for board members who often come there before board meetings to have a chat or do some homework. The board meetings are usually held in a meeting room next to the office. (F).

In Manchester, the Youth Council office is at the heart of the old Town Hall, and has been created as a cosy and welcoming space by the young people, but at the same time occupies a marginal space of an old cloakroom.

The Youth Council meets in a small room behind the reception desk of Manchester Town Hall. This is the usual room for 'The Hive' named after the Bee, the symbol 
on Manchester's coat of arms, representing the industry of Manchester. Sometimes the Hive meets in the splendour of one of the Committee Rooms and sometimes in the democratic grandeur of the Council Chamber itself. But the regular space for the meeting is in what was once perhaps a cloakroom near the side entrance. The Town Hall (completed in 1877) was built by the renowned architect Waterhouse its neo-Gothic cathedral like splendour presenting Manchester and its civic leaders to the world as men of weight and prestige. These newly enfranchised men shaped a new form of power and pride. 'What Manchester does today, the world does tomorrow.' Outside the Town Hall, a great library, built in the mid twentieth century, speaks of the place of education in the democratic civic project, and Albert Square outside the Town Hall is the physical enactment of 'the public square': a place for outdoor gatherings, for people's assemblies, even perhaps for Nuits Debout, but more probably for the announcement of corporate events of a variety of kinds such as Fun Runs. Just to the edge of Albert Square is the Friends Meeting House, still in the place where it was being built in 1819, where 11 were killed and many hundreds injured, when they gathered to demand universal suffrage in St.Peter's fields; the Peterloo Massacre. One of the aspects noted on more than one occasion is the beauty and dignity of the Town Hall spaces which the Youth Council participants occupy. (M)

In contrast to these civic places with greater or less amounts of dignity are the Youth Centres:

The youth centre $\mathrm{X}$ was built in the 90 s as an open youth work institution in Frankfurt, clearly with the idea to offer a space for marginalised and often criminalised young people in the inner city. With its space and offers for young people it creates a huge potential and diversity for appropriation, therefore the interplay of different groups of young people and their usage of space is very interesting for the project. The facilities are two recording studios, one dance space, a fitness room, a gym, a kitchen, several offices for staff members, an open meeting room and a court yard next to a playground partitioned over three levels. There is an open meeting room which is basically the core of the youth centre. (F)

This centre could have been designed by the very same company as designed the Manchester Youth Centre in our study.

The division of space internally in youth centres is most usually designated in terms of the actions rooms predominantly contain: the sport; the art form; the 'rec 
area'; the canteen. Therefore the designation 'The Girls Room' (referring to a population not a set of actions) still serves to show how normatively masculine the other spaces remain. I observed a continuous negotiation at edge of the building where young people hang about outside before deciding to come in tonight. (M).

The physicality of both the Youth Club and Youth Council spaces carries meaning and forms part of the mise-en-scène of participation ${ }^{4}$. Whereas Youth Councils are in the centre of their cities, youth clubs are at an edge. Some buildings, such as Town Halls, seem made to last, whereas others are quickly erected and made cheaply; the former signal prestige, status and difficulty of access, whereas the Youth Club buildings seek to indicate accessibility. The buildings themselves carry in their architecture messages about 'youthfulness' and 'participation', the kind of drama that might be performed there and the actions that might be played out. In the Town Hall, all is aspiration and dignity; in the Youth Centres less so.

The time of the school day and the academic year frames the drama of participation. What happens here happens at the margins or beyond the important business of schooling and so the scripts that are performed here are already marked by this relationship with school.

'The meetings start formally at 4 p.m., but the members drop in and leave as they please, mostly according to their school and after-school activities. Since this is a quite small group the atmosphere is often relaxed and casual. The group deals with whatever is on the table (in terms of topics that need to be addressed), they drink coffee and chocolate, eat fruit, and engage in conversations.' $(\mathrm{G})$

This 'filter' in attracting certain groups while excluding other by the temporalities of schooling also includes age and class: In Frankfurt there are no board members younger than 15 and the typical career of a board member is to start at 16/17 and stay until the last grade of Gymnasium. Other school types like vocational schools are also rarely represented because the 'working rhythm' does not fit the time tables of students from vocational schools who in their majority are in an apprenticeship alternating between

\footnotetext{
${ }^{4} \mathrm{We}$ concentrate on this aspect here while the appropriation processes by young people are treated in-depth elsewhere (Andersson et al., 2019).
} 
times at the company and at school. This sums up as a lack in continuity of the composition of the board

A small group which also meets fortnightly around sweet cakes and biscuits in the mid afternoon after school in the local radio station rooms (M).

Newly elected members on the board are invited to go on a week-end residential with an introduction seminar into the work of the YSR. Paula, the female board member we have interviewed, says that she has made new friends mainly due to this event and that after a couple of weeks she started to have drinks with the other board members after the sessions $(\mathrm{F})$.

There is an annual cycle of events (M).

These extracts from fieldnotes give a sense of these as highly pressurised times, time snatched away from the officially important business of schooling. And such time can only be snatched by certain people. The forms and times of these spaces are controlled externally by other rhythms, most especially those of the school day (meetings happening immediately after school or in the lunch hour), by the school week (residential experiences are offered at weekends) and by the school year (everything begins in September; this is a suitable activity for children/young people at a certain (just before final exams) grade or level and so on. Those excluded are those in vocational education whose time tables do not fit; those with other after school commitments (for example looking after siblings); or who have Saturday jobs.

In contrast with the spaces and times of the formal Youth Councils are the Youth Centres and Youth Work spaces in which the times are usually scheduled from 5.00pm until 10pm, opening also at weekends. This is still essentially shaped by the rhythms of school, to which all this practice takes second place. However, there is the potential for an alternative here to both school and family. These places are often referred to as 'like a second home' and young people move in and out of engagement in those places in a way more like home and less like a school timetable slot. This too though only applies to those young people who can find a way to the Youth Club, whose families do not disapprove of them attending such places rather than doing their homework or other more 'constructive activities' or who do not fear for their children's safety beyond the well supervised spaces of school. The intersections of gendered and racialized power dynamics and class are all too evident across all the spaces. The way young people 
from recently migrant families are claiming space and opportunity is also notable in all the cases we have analysed. These dynamics are lived through in ways which both serve to include some and marginalise others, along predictable lines, but which also have unpredictable outcomes and expression, as the next sections show.

\section{Actors and Audiences}

The awkward relationship to the dominant scripts of schooling appears at times in the formalisation (the taking on of 'school' scripts) of youth work practice which we encountered. The following example included moments in which the youth work methods take on a standardised form, and also moments in which actual scripts are used, for example in the running of a large general meeting:

As well as the formal curriculum/agenda already discussed there is what one senior practitioners referred to 'how we do things as youth workers.' This can look a bit like a strange youth work 'cult' from the outside involving a range of introductory games and ice breakers a good deal of eating; the use and development of 'participatory engagement toolkits'. (M)

The drama of power which then emerges on these stages at the edge of schooling is often intense and the youth worker/young person relation is potentially fraught.

Young participants become adept at negotiating what is being offered and finding some degree of power within it. Youth workers offer 'bribes' as a way of securing compliance with an ongoing agenda that does not derive from the here and now of young people in the space, and young people accept these 'bribes' as a basis for their occupation of the space, as is shown in the following exerts from Frankfurt fieldnotes. A youth worker combining a youth centre with outreach activities speaks of organising flexible events and projects with the aim of 'docking' children and young people step by step to the more institutionalised offer of the centre:

\footnotetext{
"I don't have to make offers if I don't orientate at their life situation ... the older ones just want a place to hang out, to meet each other and to chat with us, the younger ones are happy with activities, especially in holidays" (youth worker F) "In general, there seems to be a precarious balance between accepting and starting from young people's expressions of needs or interest and paternalistic
} 
interpretations of what young people really need. Youth centres organise music projects, provide equipment and if somebody is aggressive, there are antiaggression projects" (Rapper: 601-617). (F)

In contrast, a middle school teacher interviewed in the same city about involvement in the Youth Council formulates clear prerequisites:

"First they need to achieve their educational aims and don't fall by the wayside, then they have to have some basic discussion culture at their fingertips, to know where they can do something" (F)

The predominance of the school agenda is here made entirely explicit.

Both young people and youth workers are aware to a significant extent of the negotiations and doubleness of participation that occurs in youth work spaces, as well as a power young people need to take at times to distance some activities beyond the gaze of the youth workers, as discussed by a Sprayers group in Frankfurt:

'First, having a double identity as a group: a legal crew as a legal way to earn money and a secret one for representation, community and scene-specific positioning by spraying in forbidden areas. Second, they use the youth centre's backyard as a space for rehearsing/partying and where their presence is tacitly accepted. And third, some members succeed in connecting graffiti and official recognition through entering art colleges. '(F)

The power of the youth worker is often marked through key symbols of control and ownership of spaces, especially keys on the one hand and provision of food on the other. There are some unwritten rules: project rooms and the kitchen are unlocked by the professionals, no fisticuffs allowed, the volume will be regulated jointly, and announcements of the professionals (e.g. mealtime, cleaning up) will be followed. (F)

The professionals decide whether one gets a key or not, despite the fact that not every visitor needs a key for entering the centre.

The ambivalence in these official and unofficial scripts is present in Youth Council spaces too. There are examples of elected Councillors seeing these young people as 'too big for their boots'; relationships with workers can become difficult and patronising, especially when the young people have potentially much higher cultural capital than the staff they are working with. There are also a number of occasions when the young 
people act as icons or visual symbols, becoming mascots both for organisations and for elected politicians, offering legitimacy, or a kind of street credibility, to their appearances and brand. This felt ambivalence appears all the way through the system. The actors become at times the audience for themselves, sometimes elected politicians become the audience for the young people in order to legitimate their own performances, sometimes researchers are the audience for performances which legitimate research, and sometimes a both known and anonymous audience emerges through social media as crowd-funding resources young people and their projects in the next acts in the participation scene. In each of the cities, at the time of our study, it was the young men who most easily moved, through these complex negotiations, as key 'youth representatives' even when there was a strong presence of young women in the groups. The impact of gendered expectations in relation to both public voice (face to camera) and public service (back up crew) remained apparent.

Nonetheless, sometimes this giving attention and audience becomes a practice of compassionate witnessing in which it can be said that young people are able to authentically articulate an aspect of experience otherwise unrepresented, and in which they may possibly be authentically heard.

\section{Going through the Motions}

The ways in which the doubleness of official and unofficial scripts is negotiated can lead to a sense of banally 'going through the motions' for both youth workers and young people. This is conveyed clearly in the following field notes. It is the sense of tokenistic or inauthentic practice that brings this flatness to the fore.

While the general assembly follows the model of formal parliamentary protocols, the board sessions are rather a mix of formalised procedures and more informal rules. During our first encounter with the board we organised a group discussion with all members. During this discussion, members raised the question of the selfdefinition of the Council as a representation of all pupils and school students and the function of the board to 'transport' their interests onto different political platforms. Several members were very critical about whether the Council and the board achieve this goal. One criticism risen is the question what their legitimation was given that many pupils and students do not even know about their existence. 
One member pointed to the fact that the Council since many years stands for the support of comprehensive schools instead of the three-tier German school system with its hierarchy of Hauptschule - Realschule - Gymnasium: "I don't know how students from Gymnasiums actually see this, [actually] they don't even know [...] that the Council is endorsing this position" $(\mathrm{F})$.

There is also a sense of 'going through the motions' and some obvious sense of frustration at tokenism I would say which in one case I have heard explicitly stated as traded for opportunities (eg going to China as part of a Youth delegation). (M) A certain dissatisfaction is expressed locally about Youth Council in open access youth groups in particular districts and there is a frequently expressed view that "it only works for a certain type of young person.' There has been a strong development of access to from Special Schools on the one hand and from local sixth forms and FE Colleges on the other. (M)

The burdens of representation and of tokenism are keenly felt during the explicit discussion in Youth Council projects. These burdens are produced in part perhaps by the sense that the young people are seeing themselves as representatives in a direct sense and in part by a frequent reiteration by youth workers concerning the privilege and responsibility of 'being representative'. In other cases, young people are more instrumental in their engagement, trading a certain boredom in performing the rituals of participation for the opportunities that come to them personally as a consequence of faithful involvement in the work. Young people, therefore, are carrying a tension and ambivalence about responsibility which paradoxically seems to close down action. It contributes also to that sense of a gap within the self, to a questioning of authenticity; a performance of self-questioning in which those taking on the role of Youth representatives repeatedly rehearse a sense of lack of legitimacy: 'we are not typical young people'; 'we are not young people'.

\section{Atmospheres}

The drama of participation involves the creation of a particular atmosphere. Sometimes perhaps often an atmosphere of calm prevails, as is conveyed in this extensive recording from Gothenburg. 
P, the secretary, who coordinates and leads the overall work of the YCG, as well as the concrete work activities at the office, plays an important role. She could be characterised as an all-around utility person, steering up and planning the work of the members, bringing up issues and topics that the members need to address. She has a crucial role in the structure of the YCG and in making the work of the council possible. At the same time she takes a quite withdrawn attitude during the sessions, not saying more than she needs to, just saying and doing enough to keep the discussions and the work in progress, facilitating the meetings. She is also the link between the YCG and the 'outside'. Often, but not always, she is the initiator of issues that need to be addressed, the members then 'react' to what she is saying, and that is how dialogue and discussions get started at the office. One reflection is that her role (being a coordinator for young) is dependent on her personality and appearance - gentle, smooth, empathetic, a good listener, slow-talker, dialogic, always leaving space for the young, clearly signalling that this forum is theirs and for them - that type of qualities seem to be central in her professional role, in order to create contact and trust towards the members. ("This is their own time", she told me on one occasion, "they decide what they want to do and how. They own their time"). During one session, when the members were planning for a food conference they were organising, I wrote in my field notes: $\mathrm{P}$ is priceless: calmly and with a firm hand she directs the work forward, informs the members which steps that need to be taken, what needs to be done and what the members need to think about. She has knowledge and skill and is a great resource that humbly and with integrity leads the work forward. (G)

But the pressures created by the surrounding power games of participation, for both youth workers and young people, inevitably erupt in a range of micro-aggressions. In Manchester the forms of exclusion of national politics were marked: young people were asked not to host meetings about the European Union Referendum because of 'Purdah'. This notion of Purdah derives from Civil Service rules. Redolent of a space in which women were placed 'out of public sight', the real conflicts (whether of national politics or of small groups of aspirational and odd young people) get pushed out of sight. Purdah is the practice in certain Muslim and Hindu societies of screening women from men or strangers, especially by means of a curtain. The children and young people of Manchester Youth Council are also screened from adults and strangers, especially those deemed to be in danger of politicising them, strange though this is in a project 
concerned with democracy.

On the evidence of this period of participant observation, colonial practices remain alive and well in the heart of UK democracy. These are being transmitted in a variety of forms in the practices of 'formal' and 'authorised' youth participation. Forms of hierarchy and rule are well established, with seniority and priority assigned to those who take on the role of Members of Youth Parliament. Committee procedure is taught as are bureaucratic forms of accountability, civility of speech, and a burden of privilege and sense of responsibility towards those not present: all these things contain and constrain the voices and perspectives of the participants, who certainly become involved because they have a sense of urgency about the issues they wish to pursue. However in the 'pecking order' the disenfranchised under 18 year olds, even those who have risen through the ranks to become Members of Youth Parliament, are not at the top of the chain. The decision about no discussion of the politics of the Referendum and the imposition of Purdah appears to have been taken by Senior Council officials.

'The same evening that the decision about Purdah was announced also involved the members of the Youth Council working at The Hive on a campaign called 'Don't Hate Educate.' A new member - a Muslim boy of South Asian heritage - was systematically albeit informally excluded from the discussion all evening, as the other members engaged in banter and teasing with one another.'

The operation of a colonial power dynamic, controlling the life of the Youth Council, was all the more painfully evident as, as so often, the very diverse group of boys and girls involved in the discussion that evening consisted of about eight or nine young people of whom five were from recently migrant or non-European heritage backgrounds, with families from Zimbabwe, Nigeria and Congo. The apparently unconscious exclusion of a new member seemed itself to be a continuation of that colonial practice, taking the old form of 'divide and rule.'

In Germany, it was the practice of informal exclusion through gender which was evident:

Even though Paula claimed to be an insider in the Council after a few weeks ("In my opinion we do have a lot of contact in the Council yes. I had a drink with them and now some doors opened and yes, you get friend to those who you work with." (Council , Paula BI, 2691-2696), this self-presentation of her seemed more or less 
motivated by her high motivation of really belonging somewhere on the one hand and perhaps her reluctance to show any weakness. The other girl, Lara, was less aggressive in her self-representation and often shy, thereby she seemed like an outsider even months after our first contact. The intersectionality between age (the girls are younger than the boys), gender, network and experience challenges the female newcomers.

The micropolitics of emotions and group inclusions and exclusions which seem to go underground/backstage and are pushed beyond the boundary in Youth Council spaces seem to take centre stage in the drama of the Youth Club. The pushing to an edge is both more open and more hidden in plain sight:

'Suddenly Peter [the professional] starts screaming and displaces the couches on the platform in the open meeting room. He screams something like "What about this mess?" I can see some crushed ice between the couches and some empty cups. Peters goes on screaming and asking why the young people are so ungrateful if there is once something for free.' $(\mathrm{F})$.

As the centre is open for all young people between the ages 13 to 21 years, the girls group are not the only visitors, but the most noticeable due to their loudness and conflicts. Their presence is often marked by their acoustic and physical dominance of the scene. They engage in verbal and physical 'fun' fights with mainly boys of similar age. Remarkably often young boys and girls are running around jostling and beating each other up (strokes into the face, jump on each other's backs, tugging each other out of the window and throw each other on the ground). A typical scene from our observations is covered in one field note: "Some youngsters are playing cards at a small table with frequent changes in who is playing.

Suddenly there is hectic movement, when a couple of boys are arriving and start to tease the girls. They run after each other and beat each other laughing. One situation looks to get more serious. There is a boy asking for a cigarette. One girl with a cigarette in her hand claims not to have any. The boy grabs her arm in a rude way and then tries to extinct the cigarette on her arm. No-one of the staff members seems to be aware of this as they do not intervene. The girl runs away chased by the boy. She starts to scream. The situation calms down when others follow them" Later the girls show us their black and blue marks in a way that makes us think they are even proud of these. $(F)$. 
It is by no means straightforward to interpret the gendered power play here. There is clear and evident masculine and dominant banter and control. But the banter also includes fight back and a claim on the space by a group of young women, who, as our extended study shows, came in a certain way to claim the youth club space as their own that summer.

Beyond this edge are the liminal spaces in which workers both do and do not acknowledge certain activities in order to sustain relationship. This can be seen as the 'back stage' or 'back room' in Goffman's terms, even when it happens in plain sight: whether that is in the Facebook site that the young people set up because the professionals' own rules prevent it, or in the 'smoking area' where cannabis is smoked 'safely'. The question of who is the audience for these youth work performances is a baffling one.

In developing this argument and understanding the role of the youth workers, we have been drawn too to explore the connections between the researcher's role and that of the youth workers. We therefore turn now to a brief discussion of the gatekeeper role (Stone, 1992; Cuconato et al., 2015) in a reflexive turn which then informs the final discussion of the role of the youth worker, who operates also in a somewhat liminal space.

\section{Being a Door Opener/Gate Keeper}

In Sweden the term apparently is 'door opener'. It sounds more friendly, as if it would make a difference. Watching the gate; keeping the gate; tending to that place: most obviously it confers an ability to let in and let out. But it is always a fairly lowly and anonymous position; not high paid or with high status. The British cultural theorist Terry Eagleton, in his memoir The Gatekeeper (2001), wrote about his job as an altar boy which involved keeping various gates: between the priest and the people, but also between an enclosed order of nuns and the parish church at which they heard mass from behind a veil and received the blessed sacrament. It was his job to keep this gate, which marked something liminal and sacred.

In a network, there is a thorny moment, a prickly knotty moment in which a boundary is being crossed. The pressurised dynamics of neoliberal systems do not want there to be 
any time or attention to be given to this moment, at this point. The role of gatekeeper disappears and becomes invisible in the process of knowledge production, through the pressure to perform and produce outputs. But there is huge invisible labour in these liminal spaces. In Victorian middle class households, it was the domestic servant whose job it was to open the door. This obviously was a job done on behalf of the household in which she was a servant. When she opened the door, she had to change her apron as there must be no sign of work being undertaken in the domestic space. The labour, to be well performed, had to remain invisible, even when the worker was exhausted.

The youth worker, in both Youth Council participation projects and in Youth Clubs, resembles this lowly worker: there to enable others and make it appear that it was all their (the young people's) own work.

\section{The needs of youth work practitioners: rivalry and carnival}

Youth workers - in both Youth Council and open access Youth Work sites - can arrive exhausted into the spaces and then find themselves unable to focus effectively on relational practice. To return to the metaphor of the stage, they stop improvising and at this point they inevitably fall back on tried and tested ideas and scripts that have worked well in the past. Because of the informal nature of the space they also have the opportunity to address some of their own needs, whilst having a blind eye turned to this by the young people. There is some kind of informal, unspoken trade-off about this.

In the early autumn sessions David always led from the front with a video or series of clips and then a 'true' or 'false' type of quiz. Later on, he became quite tired and less prepared as he had taken on additional work as a classroom assistant in a Pupil Referral Unit, a primary school for children with emotional and behavioural difficulties. He returns on more than one occasion to the 'Citizenship Test' as an interesting topic but also as a consequence of the fact that he needs to take this test himself: despite having been educated in England and sounding like an Englishman David still does not have citizenship here but in Nigeria.(M)

There is a lot of talk about the Nandos meal afterwards: the famous whole chilli chicken challenge which Robert will do. The Nandos challenge happened when Kath challenged Robert when she said she would buy him a beer if he ate the whole chicken and he used the beer to clean up the carcass of the chicken. YP1: 
'Save yourself for Nandos cos Nandos is eat what you want......eat what you want.

You know in Nandos and when you don't eat your food you can take it away.'

'YP2: 'Can we do that?'YP3: 'If my brothers see it's the whole family's, they will take it.' YP4: 'Put like a juju threat on there, put some obisi on the chicken.' YP2:

'Can we have desserts?' YP4: 'We can only have desserts.' (M)

Somehow in the context of poverty there is an always possible laughter and excess and celebration as well as a kind of comradeship extended to staff who are prepared to work unsocial hours and weekends and do Christmas with young people.

\section{Discussion}

In the opening of this article we asked how bringing to the surface the dramatic and theatrical practices underlying the metaphor of performance might shift our understanding of the power dynamics of participation and the role of youth work as a pedagogic practice. It has enabled us to bring to the fore the ways that the buildings and rooms, and the time frames of the participatory practices are shaping the performance. The youth workers and the young people in these space/times can be seen as actors in the drama of participation; cast in their roles and by definition, as this is a practice that claims in some way to be related to democracy, caught up in power play, both small scale (in terms of the control of spaces) and sometimes on a larger political stage, as in the context of the UK referendum on membership of the European Union. The sense that a staging is occurring also allows recognition of the ways in which actors - both youth workers and young people - perform knowing and not knowing one another's presence and actions. These actions work concurrently with both official and unofficial scripts (Scott, 1990) and the gap between the official and unofficial scripts is the gap in which the conflicts and agonism of the participation drama emerge and in which attempts are made to suppress them (Rancière, 1998). The audience for these every day dramas is both the participants themselves (this is an immersive performance) but may also be said to be the walls and doors, and then the other occupants of the schools, youth centres, council offices and Town Halls whose buildings are the environment of these performances; also the authorities, who may request or be invited to hear and see what the young actors say and do, as well as researchers and other visitors, and occasionally a wider public. There is a politics of recognition and of appearance here (Butler, 2015; 
authors). If there is improvisation, it is not always rehearsed, but erupts perforce in these overly scripted and constrained contexts.

What then can we say or, are we provoked to consider, about the forms of democracy that are fostered and fuelled in such spaces, as a result of unearthing the theatrical aspects of the performance metaphor? There are certainly real limitations to it, and we also need to consider the limitations on our own roles as tasters, listeners, noticers and interpreters as well as gatekeepers across the city spaces with which we have engaged. Both a sense of potential achievement and leadership and also of futility are being fuelled here; both an understanding of democracy and a mistrust of it; an ambivalence fitting perhaps in cultures deeply ambivalent about their own democratic projects.

Democratic learning in the context of a great deal of unmet need, of what can seem bottomless need, is being fuelled with ambivalence, and those employed to enable can seem more marginal and vulnerable than the young people they work with at times. The pedagogues are to be found drawing a veil; closing things down; but also hanging out with; chilling; pontificating; gaping in awe; photographing; posing; taking a back seat; encouraging; arm-wrestling; mediating; advocating and staging deeply ambivalent forms of both front stage and back stage participation.

Recognition, opportunities for non-normative and alternative ways of being young together, finding a 'home', a space of acceptance, all these are elements that characterise a number of the sites which we have studied. The role of the pedagogue/youth worker in supporting young people's autonomy and development of civic agency is explicit (Fusco, 2011); how to avoid the risks of (usually inadvertently) undermining it is a much more covert issue.

\section{Conclusion}

This article has presented some of the findings of the PARTISPACE project concerning the role of the youth worker in enabling participatory pedagogies in formal and informal/non-formal settings. We have analysed these findings explicitly in terms of performance, seeing both youth workers and young people as engaged in a complex performance, whose script is to a significant extent already established, both in environments, timings and the political rules which are shaping these contexts of youth 
participation. This leads to inevitable conflicts, performed both covertly and overtly and to practices of inclusion and exclusion which follow well-trodden paths of class, colonialism and gendered practice but in which these ways of walking are also diverted from in paradoxical ways.

The extent to which these spaces enable the fuelling of democratic life is therefore uncertain and the practices are deeply ambivalent. Youth work's capacity to reflect on these ambivalences in times of a neoliberal re-programming of its nature needs to be strengthened. Nevertheless, the opportunity to support young people's autonomy, a clear pre-requisite of democracy, is present in almost all conversations with the youth workers, even when it is performed out of exhaustion as much as out of fellow-feeling for the young people, or out of the stubborn agency and determination of the young participants themselves.

\section{References}

Andersson, Björn, Yağmur Mengilli, Axel Pohl, and Christian Reutlinger. 2019. "“You can't be up there" - youth cultural participation and appropriation of space.' Discourse. Journal of Childhood and Adolescence Research 14 (1): forthcoming.

Batsleer, Janet, and Bernard Davies, eds. 2010. What is youth work? Empowering youth and community work practice. Exeter: Learning Matters.

Batsleer, Janet, Patricia Loncle, Axel Pohl, and Andreas Walther, eds. 2019. Struggle for Participation: Practices, power and pedagogies of young people in the public. London: Routledge.

Biesta, Gert, Robert Lawy, and Narcie Kelly. 2009. 'Understanding young people's citizenship learning in everyday life.' Education, Citizenship and Social 4 (1): 5-24. doi:10.1177/1746197908099374.

Butler, Judith, Ernesto Laclau, and Slavoj Žižek. 2000. Contingency, Hegemony, Universality: Contemporary Dialogues on the Left. Phronesis. London: Verso.

Butler, J. (2015). Notes toward a performative theory of assembly. Cambridge: Harvard University Press. 
Charteris, Jennifer, and Dianne Smardon. 2018. 'Student voice in learning: instrumentalism and tokenism or opportunity for altering the status and positioning of students?' Pedagogy, Culture \& Society 31 (1): 1-19. doi:10.1080/14681366.2018.1489887.

Cooper, T., 2018. ' Defining youth work: exploring the boundaries, continuity and diversity of youth work practice' SAGE Handbook of Youth Work Practice, 3-17, London, UK, Sage Publications - Reference E-Books

Cuconato, Morena, Manuela Du Bois-Reymond, and Harry Lunabba. 2015. 'Between gate-keeping and support: teachers' perception of their role in transition.' International Journal of Qualitative Studies in Education 28 (3): 311-28. doi:10.1080/09518398.2014.987854.

Eagleton, Terry. 2001. The gatekeeper: A memoir. London: Allen Lane.

Farthing, R. 2012 Why Youth Participation? Some justifications and critiques of Youth Participation using New Labour's policies as a case study. Youth and Policy 109 pp 91-97

Fusco D 2011 Advancing Youth Work Current Trends Critical Questions New York Routledge

Goffman, Erving. 1959. The presentation of self in everyday life. New York: Anchor Doubleday.

Heathfield,M. and Fusco,D. 2015. Youth and Inequality in Education Global Actions in Youth Work Routledge 2015

Lipsky, Michael. 1980. Street-level bureaucracy. Dilemmas of the individual in public services. New York: Russell Sage Foundation.

Ord, Jon. 2007. Youth work process, product and practice: Creating an authentic curriculum in work with young people. Lyme Regis: Russell House.

Percy-Smith, B. (2010). Councils, consultations and community: rethinking the spaces for children and young people's participation. Children's Geographies, 8(2), 107122.

Rancière, J. (1998). Disagreement: Politics and Philosophy. Minneapolis: University of Minnesota Press. 
Schwanenflügel, Larissa von, and Andreas Walther. 2016.

'Verjugendsozialarbeiterisierung' oder Infrastruktur der Anerkennung? Kinder- und Jugendhilfe im aktivierenden Wohlfahrtsstaat." In Vermitteln, edited by Mirjana Zipperle, Petra Bauer, Barbara Stauber, and Rainer Treptow, 309-22. Wiesbaden: Springer Fachmedien.

Scott, James C. (1990) Domination and the Arts of Resistance. Hidden Transcripts. New Haven and London Yale University Press

St. Croix, Tania de. 2016. Grassroots youth work: Policy, passion and resistance in practice. Bristol: Policy Press.

Stone, Deborah. 1992. "Gatekeeping Experts and the Control of Status Passages." In Gate-Keeping and the Life-Course, edited by Walter R. Heinz, 203-20. Weinheim: Deutscher Studien-Verlag.

Taylor, Carol, and Carol Robinson. 2009. "Student voice: theorising power and participation." Pedagogy, Culture \& Society 17 (2): 161-75. doi:10.1080/14681360902934392.

Thole, Werner, Peter Cloos, Stefan Köngeter, and Burkhard Müller. 2011. "Ethnographie der Performativität pädagogischen Handelns." In Empirische Forschung und Soziale Arbeit: Ein Studienbuch, edited by Gertrud Oelerich and Hans-Uwe Otto, 115-36. Wiesbaden: VS Verlag für Sozialwissenschaften.

Walther, A. et al (2019) Struggles for Participation? Practice,Power and Pedagogies of Young People. London. Routledge

Young, Kerry. 2006. The Art of Youth Work. Lyme Regis: Russell House Publishing. 